\title{
TRADTIONAL METHODS OF RESOLVING CONFLICTS: THE ROLE OF KURDISH AGHAS (TRIBAL LEADERS)
}

\author{
Maamoon A. Mohammed \\ Center for Peace and Conflict Resolution Studies, University of Dohuk. Kurdistan Region, Iraq
}

\begin{abstract}
Iraqi Kurdistan comprises many tribes, each with a leader or Agha who is greatly respected by that tribe and many outside it. The position is inherited from the Aghas' ancestors and, traditionally, conflict resolution is seen as their responsibility. Although primarily Muslim, they have an open-door policy and intervene in all cases of conflict that are brought to them, whether they involve social conflicts (such as blood feuds), family disputes, issues relating to honour killings, or friction between tribes.

The paper explores the ways that Aghas intervene in and resolve the most complicated cases of conflicts as well as working to rebuild the broken relationships among conflicting parties. It explains the processes they follow when resolving conflict and what makes them successful in doing so. Many Aghas have secular ideas and do not make judgements based on religion; consequently, they are also sometimes preferred as referees by non-Muslim communities. While this discussion considers the Aghas' methods to provide fair and constructive means for resolving conflicts - thus playing a significant role in maintaining stability within the multiethnic society of Iraqi Kurdistan, it also suggests ways these methods might be better supported and developed to be more relevant to contemporary society.
\end{abstract}

KEYWORDS: Mediator, Traditional methods, Agha, Conflict, Conflict resolution

\section{Introduction}

Iraq is a tribal society and traditions are prevalent in all domains of life. Throughout the country's history, whenever the state apparatus is weak, tribes and their leaders (or Aghas)- who may be Muslim, Yezidi or Turkmen, among others - have had a strong influence on the status quo (Ahmed 2013). Consequently, the culture and the traditions supported by tribal leaders are internalized in people's minds. This has been the case in Iraqi Kurdistan (IK). In relation to this, Bruinssen (1992) demonstrates the significant role that tribal leaders have played in the social structure of Kurdish society throughout history. Although, in the 1990s, the role of tribes was stronger than at present as the government institutions were not functioning so well at that time, and the Iraqi government authorities had limited or no power in IK in 1990s. Throughout history, all Iraqi governments and colonial powers have depended on tribal leaders to enable them to maintain social stability in the area. In return, historically, the Iraqi government has always depended on the Kurdish tribal leaders. For example, in the 1980s, the Iraqi government under Sadaam Hussein depended on the tribal leaders with weapons, money and privileges as a means to control the situation, which also involved fighting their brother Kurds, the Peshmerga. Thus, tribal leaders' loyalty to Iraqi governments soiled their reputation and compromised their influence on people. However, later, tribal leaders' support for the Peshmerga was the reason 
for the Iraqi government to defeat in 1991. Since the 2003 invasion, the role of tribal leaders in Iraq has been very strong and they have had significant influence in enforcing laws and establishing sustainable reconciliation (Hussein 2013).

While not seeking to play down the valuable role that the formal system plays in resolving conflicts in Dohuk, this paper focuses on the traditional methods used by Muslim Aghas (tribal leaders). The Agha is a man who, by virtue of his ancestral inheritance, fulfils the role of leading a tribe, and who is appointed in accordance with the customs and traditions of the tribe. Academic literature on this subject is very limited, making this study especially valuable in filling this gap in our understanding of traditional methods used to resolve conflicts.

Therefore, in the absence of academic precedent, after reviewing the literature on traditional conflict resolution methods in general, the paper analyses the results of recent research conducted in Dohuk City in Iraqi Kurdistan. It focuses specifically on the work of Aghas, discussing different ways and aims of dealing with conflicts and, in doing so, identifies a significant feature that distinguishes Aghas' customary approaches from official procedures. This is that the former do not lay emphasis on who is right or wrong but rather on reconciliation that avoids relapse into conflict and on ensuring that both parties are satisfied and ready to let bygones be bygones. Despite this, there are some aspects of these methods that need updating, in particular in relation to the role of women and youths play, and these are explored and suggestions made for how they might be remedied. The paper concludes that traditional methods can provide a basis for developing methods that can enable people to live together peacefully because communities in Iraqi Kurdistan not only consider themselves obliged to conform to the outcomes but are also proud to use these methods.

This paper is based on a research funded by the Gesellschaft für Internationale Zusammenarbeit (GIZ) as one of the outputs of a project for Social Cohesion, jointly implemented by Forum Civil Peace Service (ForumZFD) and the university of Dohuk (UoD) Center for Peace and Conflict Resolution Studies (CPCRS) of the University of Duhok (UoD) from October to December 2016.

\section{Traditional Methods in Context}

No community is exempt from conflicts and disputes since these exist wherever people exist. Therefore, to maintain social harmony and stability within a community, reliable and accepted mechanisms for resolving conflict are required. Supporting this, the United Nations Declaration and Program of Action on a Culture of Peace (1999: 1) states: "Peace not only is the absence of conflict, but also requires a positive, dynamic participatory process where dialogue is encouraged and conflicts are solved in a spirit of mutual understanding and cooperation".

This paper considers conflicts to be normal occurrences that may happen at any time - so the question is: How can they be resolved and prevented from escalating? However, it is important to recognize that, many times, interventions can themselves be problematic and even exacerbate conflict. Many conflicts that occur today constitute what Kaldor (2007) refers to as 'new wars' these tend to be internal, non-conversational and culturally-sensitive (cited in Boege, 2006). Consequently, they need intervention mechanisms that are culturallybased and relate specifically to the environment where they occur.

The literature demonstrates that both the causes and the resolution mechanisms of conflict are deeply rooted in the culture of every society. This has motivated many 
states to make approaches like mediation official. For example, traditional methods can be found in most countries, the US, Rwanda (where they are known as Abunzi), India (known as panchayat), Sudan (Gacaca, or locally called Judiyya), Uganda (Ekika), and Ethiopia. People's perception of the role of traditional methods is also very positive in Pakistan and Afghanistan (the Jirga) where their effectiveness has been demonstrated in many conflict situations (Search for Common Ground 2013:9). Interestingly all these ways of resolving conflicts are fundamentally different from Western ways (Reichel, 1998).

Moreover, as many people in Muslim societies tend to doubt everything that comes from Western societies, they also suspect modern methods and interventions in resolving conflicts because they think that they may connect them with Western thinking; meanwhile, traditional methods are considered legitimate by the community as they have developed from the local context. Barnes (2006) supports this, arguing that peacebuilding processes and initiatives must be embedded in local communities. Moreover, in wars and conflicts, official government institutions for resolving conflict become destabilized while the traditional methods of resolving conflicts tend to remain more dependable (Barnes, 2006).

Furthermore, because members of communities know one another, when conflict occurs the whole society is affected, social relations become fragmented and consequently conflict can escalate into violence. Therefore, it is important for the community to have shared rules that can enable them to face such challenges in a cooperative and accepted way. Therefore, the participatory dialogue mechanisms prevalent in traditional resolution methods are especially appropriate for dealing with conflicts in these communities. Mac Ginty (2008: 145-146) explains that traditional methods are considered to be based on "longestablished practice and local custom". As they are part of people's daily practice, these methods are transferred from generation to generation, especially in tribal societies like IK. Traditional methods are socially constructed, locally owned and part of society's assets and identity to the extent that many people blame those who avoid these and instead use the court system to resolve their conflicts.

Hence, traditional methods are considered strong pillars of society that guide people in how to behave and they conduct their affairs accordingly. Boege (2011: 437) highlights that these methods are "context-specific", rather than having universal applicability. Moreover, Zartman (2000: 7) argues that traditional mechanisms "have been practiced for an extended period and have evolved within ... societies rather than being the product of external importation". Thus, since people have been using these methods throughout history and some of them are written in sacred texts (for instance, in many points in the Quran), people feel obliged to practice them and feel acknowledged when they do so.

In Kurdish society, many people practice traditional methods and many people prefer traditional methods to the court system. Hamo's (2014) research indicates that the majority of people in Kurdistan prefer third party involvement in resolving conflicts to going to court: $52.3 \%$ of people surveyed had used different peaceful alternatives to resolve their conflicts; $49.8 \%$ preferred third party involvement; $40.8 \%$ of people preferred to go to Mullas to resolve their conflicts; $38.2 \%$ people used friends to resolve their conflicts; and $16.7 \%$ preferred tribal leaders to resolve their conflicts. Moreover, $67.0 \%$ were in favor of widening the role of third parties in court, considering that this would make the court more 
modern. However, some argued that there is no justice in mediations (Hamo, 2014).

Nevertheless, in order to maintain order in society, national laws that can support court decisions are needed as well as traditional ways, and these need to be accepted and respected by the people. This is in line with Aristotle's idea of law: "Law is order and good law is good order", which implies the need specifically for good laws since bad laws can bring chaos and disorder, because people react to governing laws. Hence, there is need for communities to have laws for the sake of maintaining order. However, in multi-ethnic societies, ensuring that laws are fair is problematic, particularly so when one majority group dominates the laws enacting processes. While there are many formal and informal mandates (based on different religious beliefs) for conducting mediation in resolving conflicts in Dohuk, in Kurdistan as a whole, national laws are driven by Islamic Sharia that in many ways contradict the doctrines of other religious communities living in the area. This has presented specific challenges to the practices of the existing court system in IK as the government has sought to build a governing system to answer all communities' needs and interests. Therefore, when non-Muslim communities have cases based on doctrine that contradicts that of the court system, these may be referred to be dealt with by the traditional methods of the relevant community. Moreover, many people lack knowledge of the effective role the court system can play in resolving conflicts and trust and believe that all their conflicts can only be resolved through traditional methods. Despite this, official and traditional conflict resolution institutions are able (and need) to work together to provide the stability and cultural understanding needed for a peaceful cohesive society. In line with this, in IK, the government has taken the initiative and built institutions that help in resolving conflicts through traditional means, as indicated in the findings of this research.

\section{Methodology}

This research used a qualitative approach research and included 20 structured individual interviews and 3 focus group interviews. The main target actors were those involved in resolving conflicts in the host communities of Duhok City; they included various community leaders and other people working on mitigating and preventing conflicts. Dohuk City comprises three main ethnic groups: Muslim, Yesidi and Christian and the research included all three ethnicities; however, this paper focuses on the role of Kurdish Muslim Aghas, both within their own community and in relations with other communities of all ethnicities.

The interviews aimed to answer the following questions: When do conflicts occur? Who is called to mediate them? Who will be accepted by the communities to mediate conflicts and by which criteria? Does acceptance change with type of conflict? What role do Aghas play in resolving conflicts? What is the process of resolution? What makes people come to the Agha for resolving conflict?

\section{Research challenges}

In terms of research ethics, there were particular challenges regarding the validity and reliability of the information gathered since there has been little previous research in this specific area. Different methods and steps were taken, including cross-checking between findings. Prior to undertaking the field research, desk research and literature reviews of previous studies, government policies and documents were conducted to enable cross-checking and gain knowledge about relevant cultural taboos. The involvement of a foreign assistant researcher alongside the local researchers 
helped to avoid local bias and the pitfalls of taken-forgranted knowledge, while the local researchers could provide in depth knowledge of the social context.

\section{Data Analysis}

As in Kurdistan generally, Duhok comprises many tribes, each with its own leader whom many people respect - not only by those from his own tribe but people from all tribes. Indeed, many of the Muslim Aghas interviewed confirmed that they have good connections and good relationships with minorities' leaders living in Kurdistan, including Yezidis, Christians, Arabs, Turkmen, Shabak, and Kakai. Therefore, they may intervene in cases involving internally displaced people, host communities, returnees, and refugees; these cases may be between and/or among the different groups. Since many Muslim Aghas have secular ideas and do not judge based on religion, they are sometimes preferred as referees by non-Muslim communities. They have an open-door policy and intervene in all cases of conflict that are brought to them, whether social conflicts such as blood feud, family conflicts or issues relating to honor killings; they may also resolve conflicts between other tribes.

The position of tribal leader is inherited from the ancestors and Aghas gain their skills in conflict resolution through accompanying their fathers' and grandfathers' interventions. Traditionally, resolving conflicts is understood as one of their responsibilities and interviewees explained that they feel they have the responsibility to provide security within their tribe and in their environment. The leader who is best accepted by people is the one who is generous, has charisma, is humble, has a sense of humor, and is rich and eloquent. The house of an Agha is also considered sanctuary, whenever people take refuge in the Agha's house, they are safe; whatever happens to the guest, also happens to the Agha. All the Muslim tribal leaders use the same methods, although some are stronger than others and some people obey and respect their tribal leader more than others.

The interviewed Aghas said that they feel equipped to do mediation, since they have a lot of experience in such matters. Many people accept Aghas' solutions, and people feel ashamed if they do not accept them as it is considered to be part of being moral and socially acceptable within the tribe. Aghas' way of intervention is also more confidential than the court; the majority of people feel ashamed if they sue people in court for social issues and they prefer to resolve it among themselves, which generally means to take it to their Agha.

A further reason that ensures the quality of their work is the Aghas' concern about their good reputation. Once Aghas take on a conflict case, they have an interest in its success and they are determined to resolve it otherwise it can detract from their reputation. As the interviewees explained, if people follow them and talk about the great role they played, this is the most that Aghas can ask for, and money is of less interest to them. Also, the government looks after them, so in case they need anything the government will provide it while, in return, when in difficulty, the government seeks the Aghas' support. However, the government fears Aghas' influence on people and is concerned that the role of Aghas may become too powerful as this would indicate the weakness of the authority of governmental institutions. Moreover, strengthening Aghas' power is understood as backwardness. Meanwhile, this traditional form of conflict resolution has one significant weakness; this is the lack of women and youth involvement in the decision making of issues concerning their life.

\subsection{Types of existing conflicts}


The research found that a number of different types of conflict are resolved through traditional means. These include conflicts over killing, vendetta, fights, land conflicts, children related conflicts, finance and debt conflicts, car accidents, and women related conflicts (honor and marriage related conflicts).

\subsection{Inter-tribal conflict}

When a conflict is between two tribes, especially if blood has been spilled, then Aghas are especially preferred and well placed to resolve it. For the most complicated conflicts, the government institutions find it challenging to resolve, the governmental institutions usually seek Aghas to resolve it. Informants explained that the more Aghas are involved in such cases, the easier it can be resolved.

\subsection{The procedures of Aghas' conflict resolution}

In Muslim tribes, the process starts at family level where the families or relatives of the conflicting parties try to prevent the conflict escalating and becoming known by people beyond close relations. If the conflict is not resolved at a family level it goes to the Mullah or to the Agha. How people choose to channel their conflict depends on the nature of the case. In general, since social conflicts are considered sensitive, they are first dealt with by the family, then by relatives, then Mullahs, and then by Aghas (see Figure 1 below). The Agha is considered last because this is less private as there are always people coming and going in the tribal leader's house; although the conflicting parties can ask for their cases to be dealt privately, this option is still more public than with relatives or Mullahs. The rest of the findings and discussion refers specifically to the role of Muslim Aghas although their work is often undertaken on behalf of other ethnicities and at times the process may be similar for other tribes.

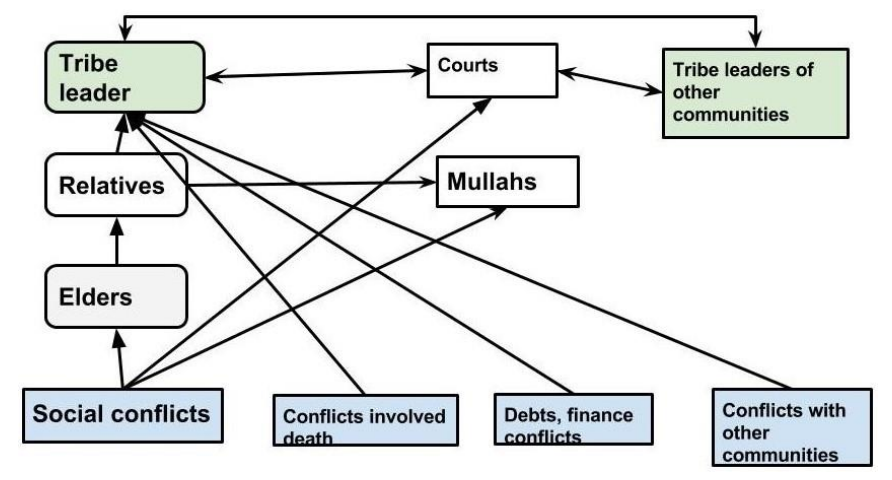

Figure 1. The referral path of conflict cases for Muslim communities in Duhok.

Resolution procedures take place in the presence of the Agha, generally in his house. Sometimes, sometimes more than one Agha may be involved. The disputants respect the presence of Aghas, they are polite and do not talk until they have asked permission from the Agha and the tribal leader has given it, then the disputant can talk. During the meeting, the conflicting parties state their case fully to the tribal leader. In some cases, witnesses are required and these are called in to state their part too. After separate deliberation with each party and their witnesses, the tribal leader tells the conflicting parties about what each says, wants, and/or needs from the other party. They also discuss the alternatives. As one tribal leader said, "conflicting parties discuss alternatives, options, and when a good alternative comes out of the discussion, tribal leaders back up the resolution [author's translation]". He also explained that "when conflicting parties arrive at a deadlock, tribal leaders provide further options until they come to a resolution [author's translation]". Conflicting parties may also discuss their conflict issue face to face, after which the tribal leader intervenes, leading them to a solution. The Aghas also tell stories relevant to the conflict situation and talk about the importance of living in peace and harmony. The resolution process can take place over several meetings and the Agha may call other people to attend if he requires people to give evidence or 
be a witness to their agreement to the resolution. Discussions go on until an agreement is reached binding one or both parties. The fact that the conflicting parties are given equal opportunities to state their case makes it possible for both parties to accept the conclusion made by the tribal leaders.

Our informants made clear that no tribal leader coerces people to come to an agreement and resolve the conflict, and conflicting parties have to understand and agree that the conflict needs to be resolved willingly. Thus, once people come to the tribal leader, it means they respect him and believe that the leader's decision will be accepted and respected. Moreover, according to a tribal leader interviewee, if a decision has been made but one or both parties refuse the decision, the tribal leader may intervene again to resolve the conflict. The tribal leader allows both conflicting parties to see the need and the possibility of concurring on the resolution and he makes an effort to ensure the conflicting parties are active participants in the process. For example, the question that is most repeated by the tribal leader is: What do conflicting parties need? This is a vital question to make it possible to bring the relationship back to normal.

Thus, the Aghas' approach is to talk to both parties, apply their mediation skills and their knowledge of the tribal traditional rules, ensure the agreement is acceptable to both parties and follow up the process; they also offer help and even provide services for the needs of the conflicting parties. Aghas welcome people and provide refreshments/food to the conflicting parties. As one community leader explained the overall procedure: "We gather the conflicting parties in the presence of other tribal leaders. Once the agreement is reached, there is high probability of success and strengthening of the relationship, and the parties do not have to worry about revenge. It is also consider an act of respect and honor to the cultural tradition not a sign of weak. As it is in court system once a party loses the case, it is difficult that the party will forget and forgive".

On many occasions, tribal leaders provide resources needed in settling the conflict if it involves financial aspect, or they may ask other people to provide financial help to the conflicting parties. One tribal leader said: "I pay from my own pocket in many cases, especially with the debt cases [author's translation]". Sometimes they collect money from the people and give it to the conflicting parties in order to resolve the conflict. When an agreement is reached that all find acceptable, the parties eat together - this of great symbolic significance. The Agha also follows up the agreement to make sure the agreement remains good.

\subsection{Relationship to official courts}

The study found that a broad spectrum of people considers it beneficial to seek tribal leaders' resolutions of conflict as these are more accepted than official methods because they conform to their society's tradition and because they are considered to be fair and unbiased. Thus, as many respondents explained, when one side in the conflict is significantly weaker than the other, the weak side is most likely to seek a tribal leader's resolution because, otherwise, the strong side may be able to get out of punishment by hiring a good lawyer to fight their case in court, or they may simply have to pay a fine. Meanwhile, in traditional resolution, the weak side will be supported by the tribal leader; moreover, the resolution is more likely to be implemented and to be respected by the strong side than that of the court. People also prefer tribal leaders' methods because they are easier and faster to set in process and the outcome is more suited to the local culture. For example, most people are not be familiar with the court procedures, which can be complicated, and it is difficult to wait a 
long time for a case to be dealt with in court, especially since the situation may deteriorate in the meantime. Moreover, Aghas are open to everyone and they are fast and free (sometimes even providing financial support), people are familiar with their rules and processes and their resolutions are more accepted in the community. Hence, in some cases, the solutions of Aghas are more accepted by people than court decisions and they are sometimes asked to intervene after the court's decision as in many cases the court does not resolve the conflict, and people still seek revenge after the authorities free the perpetrator, no matter how long they spent in prison.

Despite their own confidence in their abilities, our research found that none of the mediators interviewed preferred mediation to the court. They argued that court is more modernized and traditions are backward. Indeed, there was consensus among these mediators from the city of Duhok that it is better for conflict cases to go to the courts. However, no matter what tribal leaders want, people respect them, especially when it comes to the resolution of complicated issues. As one interviewed community leader said: "Despite that the fact we tell people not to come to us and we refer them to the court, on many occasions, they come to us after their conflict was resolved in the court and they want to be reconciled as in the court there is no reconciliation there is win lose situation". On the other hand, one interviewed Agha said that some educated people may not like to refer their conflict cases to Aghas, since they consider their traditional methods to be backward and conservative. They prefer their conflict cases to go to court.

The tribal leaders also have some influence in government institutions; as one interviewed Agha explained, they have the ability to ask the courts to postpone a case until an Agha has attempted to resolve it. Moreover, Aghas' success and their acceptance by local people has led the government to open other community-based institutions for resolving conflicts before the case goes to the court, such as a consultancy for violence against women, committees of political parties, and committees of elders in every village to resolve village conflicts.

\section{Challenges}

Despite the excellent role that tribal leaders play in resolving conflict, and in fostering reconciliation and stability in the community, they face significant challenges. For instance, there are differences between the judicial laws and customary laws with the latter being regarded as backward and the judicial laws as more modern. Moreover, they are often in contradiction and sometimes the court may punish people for their wrong doing while a tribal leader's decision on a similar case is to free that person without punishment.

In certain cases, the lack of official status attributed to tribal leaders' decisions inhibits people from going to tribal leaders. In addition, some people need their agreement to be endorsed by the government institution especially if the case needs to be documented. Consequently, disputants may use the service provided by tribal leaders and, once they have come to an agreement, they go to the court for the routine procedures to ratify it. A similar problem stems from the fact that, unless the decision has been validated in court, the conflicting parties can break an agreement if they later feel there is insufficient justice in the mediation process conducted by the Agha. But, since an Agha's reputation is very important, he will make a great effort for the decision to be fair and because the decision is not obligatory, this put more pressure on the Agha to ensure the process is just and sensitive to both parties' needs. Since the Agha is a part of the community there are few 
problems relating to access, however, sometimes it is difficult to find privacy for the resolution procedure as the Agha's house may not be big enough to allow this. There is also a lot of demand for his services; Agha cannot deal with all cases if too many cases come to him at once. Sometimes they face challenges that require them to help their communities through 'thick and thin' times.

For instance, one tribal leader explained that he "sometimes gets to intervene in cases at a very late time, and other times he had to travel late in the evening to far places [author's translation]".

The lack of women in decision-making roles also presents major challenges in traditional conflict resolution. In Kurdistan, power is predominately in the hands of men and they are unwilling to share and extend the same status positions and privilege to women. This is difficult to resolve because, as one tribal leader stated, "People have been culturally socialized that women cannot be leaders, and they have internalized this idea and it will take time before people accept it [author's translation]". As a result, women are mostly left disadvantaged in customary law practice. Furthermore, when the case involves emotional and psychological damage, tribal leaders find it difficult to make reparation and give the victims their rights back. This is especially challenging in cases that involve women and children's rights, because of the patriarchal nature of society, so women rights and emotions are not considered important issues. Moreover, there are no simple measures or written regulations for handling emotional and psychological harm. Therefore, tribal leaders need to learn to play the role of psychologists or counselors to try to help the victims; for some this is natural but for others it is very difficult.

\section{DISCUSSION}

Consideration of the findings presented above highlights several features that make the work of Aghas especially effective in Kurdish society. These include the importance of restitution and restoration, reconciliation, and genuine acceptance of the obligations implied in the resolution outcome; all of which are necessary for reinforcing a harmonious cohesive society.

\subsection{Restitution and restoration as moral obligation and} duty in Kurdish society

People in the local Muslim community believe in restitution and restoration because, when repenting to God, restitution and restoration need to be implemented for repentance to be accepted. Thus, when people have taken what belongs to another - this can involve transgressing their rights or stealing material assets restitution requires compensating for the damage caused by the loss while restoration involves replacing or bringing back what has been stolen. Because tribal leaders are so close to their communities, they are able to act as people's guardians ensuring that this process is enacted.

In general, the community considers the tribal leaders' focus on a process involving retribution and restoration preferential to a prison sentence for a number of reasons:

- They think that it means that offending parties can learn the lesson that one cannot do wrong things and get away with it. Moreover, they learn this without going to prison, which is generally believed to make people more criminal.

- These methods reinforce the social bonds of the community - in contrast to court decisions that often increase divisions between people.

- There is more chance of a positive outcome in that the perpetrator has the opportunity of moving on with life rather than going to the prison, which could spoil his/her life and jeopardize other daily 
responsibilities and activities. However, there are exceptions; for example, when the tribal leader and the community know that the perpetrator is a habitual offender. In such a case, many people (including the tribal leader) prefer that he/she to be removed from the community and so prison would be considered the most appropriate and acceptable solution.

- If the offender spends time in prison without making restitution or restoration, the issue may not be resolved.

\subsection{Reconciliation}

The issue and aim of the tribal leaders' role is not about deciding who wins or loses but to reconcile both parties through mediation. Therefore, Aghas' resolution is a process that includes reconciliation; this requires reestablishing broken relationships, forgiveness, creation of the means for commonsense building, and agreement on a common narrative of the past. Therefore, the process requires follow up so the tribal leader can make sure that conflicting parties reconcile and forgive one another. This comes from wisdom associated with Islamic texts of the Quran, from the ancestors and inherited generational wisdom, and from elders' sayings that encourage forgiveness. Since these Aghas' communities are Muslim, they have faith in Quranic verses that support this; for example, "Hold to forgiveness; command what is right; But turn away from the ignorant verse 199). A shared goal of traditional mediators is to develop a community that is united; since the stability of a community depends on relations within and between communities, the reestablishment of social bonds through reconciliation of the conflicting parties is important for the stability of the society.

\subsection{Obligations of the aggrieved and the wrongdoer}

The family and the community play a big role, and have a significant stake in the process of forgiveness and letting 'bygones be bygones'. The acknowledgment of the wrongdoing in conflict by one or both parties is vital to create a ready atmosphere for reparation and remorse which, consequently, can then be followed by forgiveness and reconciliation between and among those in dispute.

Moreover, the act of forgiveness can be attributed to both the perpetrator and the victim. The perpetrator has to acknowledge the wrong done and ask the victim for forgiveness. He/she has a moral obligation not to repeat the offence in the community. The victim also has to acknowledge the wrong done and accept the apology from the perpetrator, thus forgiving him/her. $\mathrm{He} / \mathrm{she}$ has a moral obligation to accept and forgive the wrongdoer. The conflicting parties' acceptance of restoration can create and strengthen social bonds and harmony among parties.

\subsection{Serious acceptance of resolution}

While people feel obliged to keep to an agreement once it is made, they are not afraid to refuse the initial resolution of conflicts; they are not coerced to accept the decision and they are free to refuse it. With this in mind, tribal leaders are concerned that people at disputes do not prematurely agree to a settlement without genuinely meaning it. This is emphasized by Galtung (1996: 89) as necessary to achieving a sustainable resolution: "if outside parties (sometimes called mediators) use carrots and sticks, paying the parties for accepting and punishing them if they do not, then there is no real acceptability or sustainability, unless one assumes that the mediators are parts of the conflict formation, not outside...".

In making and following up the implementation of the agreement, the process that tribal leaders follow aims to 
make sure that when people agree on the resolution they really mean it and they speak for all involved on their side. Even though the resolution may take time, when they accept the decision they are fully satisfied with it since shame is only attached if conflicting parties did not try to resolve the conflict or do not honor their agreed obligations. This is important in a community: conflicting parties need to reach an agreement and be satisfied with it as acceptance alone, without genuine belief in the resolution, can mean long term protracted bad relations. This may mean avoidance of talking about conflict, thus, allowing the issues involved to fester and the conflict may then be rekindled at any time. Moreover, this has damaging effects on the relationships between people close to the disputants and their relatives.

In this close-knit communal society, when two people are in conflict the immediate family and relatives are affected and all will bear their part of negative consequences as they will not talk to one another and all relatives will be under threat. Hence, since the tribal leader knows this reality, this is why the resolution of the conflict is not decided at one sitting but is a process developed in several steps whereby disputants discuss the conflict and its resolution over several meetings. Then, when they sit and eat together, they make a first step to re-establishing harmonious relations. Moreover, by being careful to follow up the implementation of the resolutions through further meeting(s) in the presence of their relatives and close associates, the tribal leader ensures that the process continues to be harmonious. This is especially important when the case is complicated and involved the death of some people. This respect for all those affected reflects Galtung's (1996:89) argument that, "the most naive view one can possibly have on conflict is to believe that the conflict is solved once the elites from the parties of the conflict formation have accepted the solution, as indicated by their signatures on some document outlining the new formation".

This process also makes it possible for the tribal leader to distinguish whether the conflicting parties are telling the truth regarding their decision to accept a proposed resolution, and to intervene again if necessary. Hence, the tribal leaders do not rush to a conclusion, and the process involved in implementation is a necessary part of re-establishing community cohesion.

\subsection{What makes the process successful}

The effectiveness of tribal leaders' work is largely due to their status as traditional, influential and authoritative figures in the community and that they are recognized as representing the whole community. This confirms the work of scholars such as Weber (2009) who identifies three sources of authority and influence: rational authority, which is derived from rules and laws; traditional authority, which is derived from the traditions a society lives by; and charismatic authority gained from the character of an individual. Similarly, Bourdieu (1991) understood the character of leadership as based on cultural, social, and symbolic capital. The Aghas' cultural and traditional capital means they have a complex understanding of the issues and the experiences of their local people as they live with them and have relevant life experiences. Their role involves generosity by tradition, as well as status and this imbues them with charisma, symbolic power and authority; moreover, they gain certain skills such as oratory and rational debating skills through their upbringing, which enables them to be influential and fair.

\subsection{What would make it more effective}

While the Aghas do excellent work, in order to promote a more balanced and cohesive society, the mediation process needs to be developed to be fairer and more 
inclusive of all societal groups; moreover, it should not be restricted to tribes and religious groups. The most common resolution methods currently used by Aghas are essential power-based and have much in common with arbitration, as practiced in court and sometimes by Mullas, in that power imbalances are prevalent. In particular, these methods are enacted entirely by adult men in positions of power and the Kurdistan context does not promote or encourage local and grassroots initiatives in mediating; rather, this is always left to the elders and tribal leaders. Moreover, the voices of women and youths are neglected and, in many cases, their rights are violated and their voices are not heard. Indeed, women are frequently used as bargaining tools in resolutions where a woman may be given in marriage as a means to rebuild the relationship between conflicting parties and, although this often succeeds and encourages reconciliation, it generally happens without the consent of the girl. Therefore, to ensure that agreements are more likely to produce balanced results that suit all groups in society, this paper proposes that more the transformative techniques of restorative justice need to be considered. These are mediation techniques that are in some ways similar to those already used by Aghas and other tribal leaders but which are more responsive to the needs of all involved whatever their social status. For instance, community conferencing is a method used by in numerous multi-ethnic societies, including South Africa, whereby, rather than suggesting solutions, the mediator takes the role of facilitator and provides opportunities for lessons to be learnt from the processes involved in the mediation; meanwhile, instead of the conflicting parties simply presenting their cases, all those affected by the conflict are involved in discussing ways of finding a solution. As the process is open to all levels of society, women could be involved in this, ensuring and encouraging better gender integration which would improve outcomes significantly. This is the form of mediation that best suits multi-ethnic societies as it very responsive to the cultural context and gives power to powerless people by allowing all stakeholders to have a voice and participate in the decision-making process

The far-reaching significance of this is explained by Lederach's (1997) peacebuilding pyramid which shows the three different levels of leadership involved in most conflicts, each level with its own approach to building peace. The top level in this context comprises the government or military elites, who are visible and known to everybody and who focus on the macro-level of conflict. The middle level involves community leaders (including Aghas), NGO leaders and academics; while the bottom level is the grassroots people who deal with the everyday activities of peacebuilding. It is this bottom level that is most neglected in current mediation processes, and which restorative justice would most benefit.

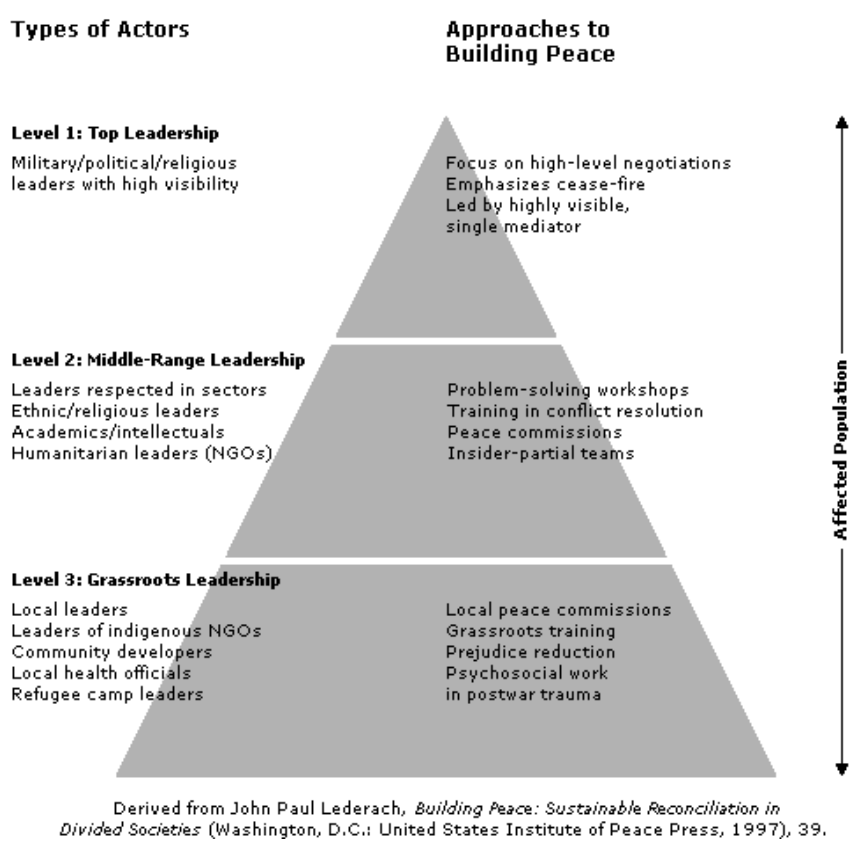

Figure 2. Lederach's peacebuilding pyramid 
Regarding the specific situation in IK, currently, only the top and middle level people are involved in conflict resolution and consequently the needs and perspectives of the grassroots can be neglected, although the work of Aghas provides a means of being more directly responsive to their people than others involved in resolution at these levels. Meanwhile, as Lederach's (2000) work shows, when space is given to communities to elicit their own conflict transformation models, they are able to bring cultural wisdom to the mediation table in a way that contextualizes both the conflict and the potential means of resolution. Local ownership and the bottom-up approach are necessary conditions for peacebuilding in post-conflict societies. This also supports and complements the middle level mediators (Lederach, 2000).

Therefore, to enhance conflict resolution at all levels, mediators need to be trained and exposed to different methods of mediation. Some aspects of traditional methods, such as their emphasis on reconciliation and their in depth understanding of the social context, can be developed to include women since women mediators are better able to understand women concerns and how stigma and taboo affects these. Meanwhile the introduction of community conferencing would enable lessons to be taken from the process involved. Ideally, these would involve tribal leaders or, if they are not able to participate, their sons, who will be the future mediators. Moreover, to ensure resolution processes are inclusive in practice, we need to support training for women, youths, and children in schools so they can benefit from the process of community conferencing, and so

understand that conflict resolution can be a positive, transformative process. If this also involved police officers and court officials, it would further increase people's recognition and confidence in the process of traditional methods. Combined with this, including youth groups who are aware of issues affecting the next generation would make mediations more effective as, according to the interviews discussed above, the process is considered by many to be outdated and backward. Overall, this paper contends that the processes used by Aghas provides an effective valuable method that needs to be updated, given more recognition, and made available for use by all sectors of society.

\section{CONCLUSIONS}

Good roles play an important part in supporting peace and stability in any place and the Aghas represent very good role models for this. Meanwhile, as Miall (2007) contends, conflicts are inevitable due to social change and, therefore, in order to avoid their intensification into violent conflict, amicable measures need to be carried out. In Kurdistan, such measures need to include supporting the customary use of tribal leaders in resolving conflicts with techniques involving restorative justice. This is in line with Bonta (1996:410), who states that "A peaceful society is presented as one in which conflict is resolved through debate and compromise and where the rule of law is effective, thus providing the conditions for stability". The process that Aghas follow in resolving conflicts - and their focus on genuine acceptance and reconciliation - plays a vital role in strengthening societal stability and cohesion. Since people will always continue to wrong their fellows, it is important to have mechanisms that not only resolve disagreements in the short term but can also unite and rebuild the relationship between conflicting parties since without reconciliation their future ability to work together constructively in the community will be compromised.

The traditional methods of resolving conflict used by 
Muslim Aghas have many advantages; in particular, their emphasis on restitution and restoration, reconciliation, obligation and genuine acceptance provide a culturally relevant road map for developing effective methods for contemporary society. They provide an economical and relatively fast means to terminate conflicts, and they are widely available and preferred by most communities. More importantly, people know what to expect and have the choice to accept the Agha's decision or refuse it. In contrast, in the formal approach, the fear of the unknown deters people from using the court and, when they do, the decision has to be accepted by the conflicting parties whether they like it or not. Moreover, success is an outcome of the influential position that Aghas play in resolving conflict - which in turn depends on that success - and thus they are well placed to provide a way to develop a more peaceful, stable society. This is due to the extensive experience that they have gained throughout their lives and the trust the community has in them, as well as the knowledge, wisdom and understanding that make tribal leaders the most appropriate persons to play this role. They are also best placed to develop their methods to be more inclusive and to complement them with community-based techniques such as community conferencing. Meanwhile, more formal recognition would enhance customary mediators' validity, and including the traditional methods of Kurdistan in official approaches to resolution will enhance their ability to provide a fair and accepted service.

\section{REFERENCES}

1. Barnes, C. (2006). Governments and civil society organisations: Issues in working together towards peace. Discussion paper for GPPAC Strategy Meeting. The Hague: European Centre for Conflict Prevention, 25 October 2006.

2. Boege, V. (2006). Traditional approaches to conflict transformation: Potential and limits. Breghof Research Centre for Constructive Conflict Management. Retrieved March 10, 2010, from http://www.berghof-handbook.nd
3. Boege, V. (2011). Potentials and Limits of Traditional Approaches in Peacebuilding. In B. Austin, M. Fischer \& H. J. Giessmann (Eds.), Advancing Conflict Transformation: The Berghof Handbook II (445-449). Barbara Budrich Publishers, Opladen/Farmington Hills.

4. Bonta, B. D. (1996). Conflict Resolution among Peaceful Societies: The Culture of Peacefulness. Journal of Peace Research, 33(4), 403-420.

5. Bourdieu, P. (1991). Language and Symbolic Power. Cambridge, MA: Harvard University Press.

6. Board of Relief and Humanities (BRHA) Duhok (2016). IDPs and Refugees in Duhok Governorate: Profile and General Information. Retrieved January 6, 2018, from http://www.brhaduhok.org/brha_du/stories/idps-and-refugees-in-duhokgovernorate

7. Bruinessen, Martin Van (1992) Agha, Shaikh and State: The Social and Political Structures of Kurdistan. Zed Books.

8. Deutsch, M. (1973). The Resolution of Conflict. New Haven: Yale University Press.

9. Galtung, J. (1996). Peace by peaceful means: peace and conflict, development and civilization. London UK: Sage Publications.

10. Hamo, Breendar (2014) Mediation in Kurdistan. Unpublished MA. University of Dohuk. College of Law and Political sciences.

11. Hassin, A. (2013). Tribes and conflict management in Iraq. Proceedings of Communication and Conflict 3rd Global Conference 2013, (pp. 1-13). Oxford, UK.

12. Hobsbawm, E. (1983). Inventing Traditions. In E. Hobsbawm \& T. Ranger. (Eds.). The Invention of Tradition (1-13). Cambridge UK: University Press.

13. International Organization for Migration (IOM) (2014). Iraq Crisis Response Displacement Map. Retrieved June 12, 2017, from http://reliefweb.int/report/iraq/iraq-crisis-responsedisplacement-map-23-august-2014

14. Lederach, J.P. (2000) Journey from resolution to transformative peacebuilding. In: Sampson, C \& Lederach. J. P. (Eds.). From the ground up: Mennonite contributions to international peacebuilding, (45-55). Oxford, Oxford University Press.

15. Lederach, J.P. (1997). Building peace: Sustainable reconciliation in divided societies. Washington DC: United States Institute for Peace.

16. Mac Ginty, R. (2008). Indigenous Peace-Making versus the Liberal Peace. Cooperation and Conflict, 43(2), 139-163.

17. Miall, H. (2007). Emergent Conflict and Peaceful Change. Basingstoke UK, New York: Palgrave Macmillan.

18. Quran, online version, an Authorized English Version, Translated from the original by Dr. Rashad Khalifa, PhD.

19. Reichel, P. (1998). Comparative Criminal Justice Systems, New York: Prentice-Hall.

20. Search for Common Ground (SFCG) (2013). Understanding the Dynamics of Conflict and Peacebuilding in Pakistan, A Perception Study. Pakistan: Search for Common Ground Pakistan.

21. United Nations Declaration and Program of Action on a Culture of Peace (1999). Retrieved January 5, 2018, from 
https://www.sgi-usa.org/wp-

content/uploads/2014/05/CultureofPeaceBooklet.pdf

22. Van Bruinessen, M. (1992). Agha, Shaikh and State. The Social and Political Structures of Kurdistan. London: Zed Books.

23. Van Cott, Donna L. (2000). A Political Analysis of Legal Pluralism in Bolivia and Colombia, Journal of Latin American Studies, 32, 207-234.

24. Weber, M. (2009). The Theory of Social and Economic Organization. New York: Simon and Schuster.

25. Zartman, W. I. (Ed.) (2000). Traditional Cures for Modern Conflicts: African Conflict "Medicine". Boulder, CO: Lynne Rienner Publishers, Inc. 